\title{
Fog and rain attenuation characterization and performance of terrestrial free space optical communication in Akure, Nigeria
}

\author{
Ajewole M. O. ${ }^{1}$, Owolawi P. A. ${ }^{2}$, Ojo J. S*3, Adetunji R. M. ${ }^{4}$ \\ ${ }^{1,3,4}$ Department of Physisc, Federal University of Technology, Nigeria \\ ${ }^{2}$ Department of Computer Engineering, Tshwane University of Technology, South Africa \\ *Corresponding author, e-mail: ojojs_74@futa.edu.ng ${ }^{3}$
}

\begin{abstract}
Reliable broadband communication requires secure high data rate and bandwidth links. With the observed increase in broadband users, known communication systems such as $R F$ and microwave links cannot promise such requirements due to link interference and low bandwidth. A current communication system that promises such requirements and more is Free Space Optical (FSO) communication. This system basically involves the transmission of signal-modulated optical radiation from a transmitter to a receiver through the atmosphere or outer space. However, location-variant atmospheric channel degrades the performance of an FSO system under severe atmospheric conditions, thus necessitating local atmospheric attenuation studies.

This paper presents the characterization of both fog-and rain-induced attenuation and the performance of an FSO system in a terrestrial terrain at Akure, Nigeria. One-year archived visibility data and in-situ measured 1minute integration time rain rate data obtained from Nigerian Meteorological Agency (NIMET) and the Department of Physics, Federal University of Technology, Akure were used to compute the fog-and rain-induced specific attenuations using Kruse model and Carboneur model respectively. The performance of the FSO system is analyzed through link margin by using the parameters of a commercial optical transceiver, Terescope 5000.
\end{abstract}

Keywords: free space optics (FSO), fog and visibility, rain, specific attenuation, probability, link margin

Copyright $(2019$ APTIKOM - All rights reserved.

\section{Introduction}

In the simplest form, communication is the transfer of information from one point to another through a transmitting medium. There are different transmitting media for conveying signals from a transmitter to receiver, which is the basis for the different types of communication technologies that exist today. Most common media include cable, plastic or glass strands and free space (the atmosphere). With advancement in communication technology, calls and data now travel hundreds of miles in a short period when converted and sent as light through plastic or glass strands between two terminals in a form of communication is referred to as fibre optics communication. Radio frequency (RF) and microwave links have also been known to provide users mobility within a signal coverage region. However, these two systems have limitations for current secure high data rate and bandwidth demands of modern broadband communication applications. RF links have problems such as congested spectrum, low transmission data rate, expensive license acquisition, data insecurity, high cost of installation and accessibility [1]. Optical fibre also have limitations such as high installation cost, high cost of equipment, long period of installation, long period of right-of-way acquisition, etc.

The aforementioned short-comings have engineered the emergence, investigation and deployment of optical wireless communication (OWC) as an alternative communication technology. In outdoor use, OWC is referred to as FSO communication. FSO communication is a line-of-sight (LOS) communication technology that involves the transmission of signals (data, voice or video) as optical radiation (laser) through unguided atmospheric channels between two transceivers [1]. It is a cost effective, license-free, and high bandwidth access technology, which has attracted significant attention recently for a variety of applications [2, 3]. Current FSO communication applications include last-mile access network, teleconferencing, inter-satellite links, optical fibre backup, campus internet interlinks [1].

A typical FSO system has three segments namely: the transmitter, the atmospheric channel, and the receiver. Of the three segments, the atmospheric channel is the most unpredictable and location-variant. Despite the overwhelming qualities of the technology, it is unfortunate that the system is adversely affected by abnormal atmospheric conditions. One of the atmospheric conditions mitigating FSO channels' availability and reliability is the presence of hydrometeors in the atmosphere, causing the attenuation of the 
signals. These include fog, rain, snow, haze, midst, etc. Among the hydrometeors, fog is the most deleterious to an FSO system [4]. Research studies have shown that attenuation in FSO system has peak value of about $480 \mathrm{~dB} / \mathrm{km}$ under dense maritime fog [5]. In this paper, the impairments caused by fog and rain on an FSO link system in the study area are presented. The remainder of this paper is organized as follows: Section 2 presents FSO Impairing Hydrometeors. Section 3 presents Study Area and Data Used. Section 4 presents Research Methodology. Section 5 presents Results and Discussion. Section 6 presents Conclusion. Section 7 presents Recommendation.

\section{Research Method}

FSO Impairing Hydrometeors, Hydrometeor is the general term referring to the products of condensation of water vapour in the atmosphere. It is usually observed as rain, hail, ice, fog, cloud or snow. The most deterrent of these hydrometeors to FSO communications is fog. It poses the greatest threat to the links' availability and reliability, although others also contribute minimal degree of degradation to the links. Since the current study focuses on fog- and rain-induced attenuations on an FSO link system, detailed account on only these two hydrometeors are presented in the following sections.

\subsection{Fog and Visibility}

Fog is a product of suspended cooled air close to the surface of the earth. It is composed of an aggregate of very fine water droplets. Fog formation is dependent on the meteorological state of the atmosphere close to ground. The meteorological conditions include relative humidity (the ratio of absolute humidity to saturation), temperature and dew point. Fog formation results whenever there is a significant increase in the relative humidity above $85 \%$, and the difference between temperature and dew point is less than or equal to 3 oC [6]. Two basic types of fog are radiation fog and maritime fog. Radiation fog is formed by temperature inversion. At the end of day, the accumulated of long wave radiation in the ground (the earth's surface) is released upwards into the atmosphere. This makes the pocket of air high up in the atmosphere warmer and lighter, thus floating over a denser and cooler one that subsides downward below it. Once the cooling effect continues to and beyond the point where the relative humidity is $85 \%$, then radiation fog is formed. Although fog particle size varies spatially and temporally, majority of the radiation fog particles droplets have a diameter around 1-3 $\mu \mathrm{m}$. Maritime fog on the other hand is formed due to the movement of damp air over a cold or water surface. It is characterized by particle diameter close to $20 \mu \mathrm{m}[1]$.

An obvious effect of fog event is that it blurs vision by reducing the clarity and extent of view. The meteorological term used to describe the extent of view in a foggy atmosphere is visibility. Visibility is a linear measurement of distance (in $\mathrm{km}$ ) which is used to describe the intensity of fog. Visibility is the measure of meteorological visual range (MVR), the distance at which an object reduces to a defined percentage of its original size [1]. Generally speaking, an atmosphere is meteorologically regarded as being foggy when the visibility is just less than $1 \mathrm{~km}$ [4]. Visibility is measured with a transmissometer which is usually installed close to the ground in a wide open lateral terrain.

\subsection{Rain}

Rain is the condensation of water falling downwards from a cloud. It is a natural phenomenon that has both temporal and spatial variability. Its effects, especially those with high rain rate, produce an attenuating effect which contributes to the unreliability of an FSO links, or outright unavailability of radio waves (absorption) with frequencies above $10 \mathrm{GHz}$ on microwave links. There are basically two types of rain namely: Convective rain and Stratiform rain. In the tropics, in most cases, occurs in the form of cells which are a complex mixture of both convective and stratiform rains accounting for about $70 \%$ or more of the total rain in most cases [7].

Convective rains have associated features that characterize them such as high rain rates, short durations (usually less than an hour) and small areas coverage (few kilometers). Two basic sub-divisions of convective rain are shower and thunderstorm. Shower rainfall is characterized by high rainfall intensities ranging from about $30-120 \mathrm{~mm} / \mathrm{hr}$, but with extremely small mean raindrop size of about $2 \mathrm{~mm}$ diameter and short duration of about half an hour. Thunderstorm rainfall is more intense than shower rainfall, having characteristics than include short-lived turbulent weather like lightning, thunder and wind, dense cloud, and heavy downpour. It has larger raindrop sizes usually greater than $4 \mathrm{~mm}$ diameter, and higher rain rate in the range $50-180 \mathrm{~mm} / \mathrm{hr}$ [8]. Startiform rainfall is usually characterized as a medium and low intensity rainfall, having longer duration (several hours) and extending over a wider area (several kilometers). Two subdivisions of this type of rain are drizzle and widespread. Drizzle rainfall is characterized by very small

APTIKOM J. CSIT Vol. 4, No. 3, 2019 : 125 - 134 
raindrop sizes, usually less than $1 \mathrm{~mm}$ diameter, and very low rain rate, with typical values between $1-5$ $\mathrm{mm} / \mathrm{hr}$. Drizzle rain is not easily analyzed on the tipping bucket measurement because of its very low intensity and long integration time involved. Widespread rainfall consists of raindrops with diameters in the range $1-3.5 \mathrm{~mm}$, and occurs fairly steadily and uniformly over relatively large areas. Widespread rainfall usually last for some hours [8].

\section{Study Area and Data}

The study area of the current research is Akure, Ondo State, southwestern Nigeria. It has a latitude of $7.17^{\circ} \mathrm{N}$ and longitude of $5.18^{\circ} \mathrm{E}$, and is $315 \mathrm{~m}$ above sea level. The climate in Akure is tropical with high intensity rainfalls observed in the summer and very little rainfall observed in the winter. Two sets of data were used in this study. The first data consist of 1-year visibility archive data (January, 2012 - December, 2012) which was obtained from Nigerian Meteorological Agency (NIMET). The second data consists of 1year time rain rate (November, 2013 - October, 2014) which was retrieved from the data logger of the indoor unit of the Davis Vantage Vue electronic weather station in the Department of Physics, Federal University of Technology, Akure.

\section{Research Methodology}

Two atmospheric loss sources (attenuation by fog and rain) are considered in the current study. For the fog-induced atmospheric loss, the specific attenuation suffered by a modulated optical radiation is a function of a number of parameters namely: visibility, transmittance threshold, and wavelengths. The Kruse model was selected for this study amongst other fog-induced attenuation prediction models because it was originally formulated for hazy atmospheric conditions with visibility much higher than $1 \mathrm{~km}$ [1], which is the case with the majority of the visibility values of the study area.

\subsection{Fog-induced Specific Attenuation (F-SA)}

Specific attenuation refers to signal loss per unit length. Thus, fog-induced specific attenuation $(\mathrm{dB} / \mathrm{km})$ by Kruse model is expressed as [1]:

$$
\beta_{\text {spec }}=\frac{10 \log T_{t h}}{V(k m)}\left(\frac{\lambda}{\lambda_{0}}\right)^{-q}
$$

where $V(\mathrm{~km})$ is the visibility, $T_{t h}$ is the transmittance threshold, $\lambda(\mathrm{nm})$ is the optical wavelength, and $\lambda_{0}$ is the maximum spectrum wavelength of the solar band $(550 \mathrm{~nm})$. For this model, the values of the index ' $q$ ' in (1) depend on visibility ranges as:

$$
q=\left\{\begin{array}{c}
1.6 \text { if } V>50 \mathrm{~km} \\
1.3 \text { if } 6 \mathrm{~km}<V<50 \mathrm{~km} \\
0.585 V^{1 / 3} \text { if } 0 \mathrm{~km}<V<6 \mathrm{~km}
\end{array}\right.
$$

Terrestrial FSO communication makes use of $2 \%$ transmittance threshold. As such, the value was used with the archive visibility data for five optical wavelengths of 650, 750, 850, 950 and $1550 \mathrm{~nm}$.

\subsection{Probability Distribution of Encountering Fog-induced Specific Attenuation at Different Wavelengths and Transmittance Thresholds Values}

Probability is a statistical concept that studies the chance or propensity of occurrence of an event. More than just a numerical entity that counts the number of occurrences of an event or experimental outcome, probability is a rational entity that showcases the relative chance of occurrence of an event under consideration. Given a sample space $\mathrm{n}(\mathrm{S})$ and number of experimental outcomes $\mathrm{n}(\mathrm{E})$, the percentage probability of occurrence of the outcome is given as:

$$
P(E)=\frac{\text { number of experimental outcome }}{\text { sample space }} \times 100 \%=\frac{\mathrm{n}(\mathrm{E})}{\mathrm{n}(\mathrm{S})} \times 100 \%
$$

The percentage probability of encountering varying degree of fog-induced specific attenuation at different wavelength and transmittance threshold values was computed using (3). ' $E$ ' is the event of fog-

Fog and rain attenuation characterization and performance of terrestrial free... (Ajewole M. O.) 
induced specific attenuation within a defined range, ' $n(E)$ ' is the corresponding numerical value, while $\mathrm{n}(\mathrm{S})$ is defined as sample space for the total number of attenuation values.

\subsection{Rain-induced Specific Attenuation (R-SA)}

Although fog is the major factor causing signal degradation of optical radiation in an FSO channel, rain also contributes some degree of degradation to the link. In this study, attenuation due to rain was considered due to its predominance in the weather pattern of the study area. The atmospheric loss due to rain, $\propto_{\text {rain }}$ in terms of its precipitation rate $R_{p t}$, is expressed as [9]:

$$
\propto_{\text {rain }}=1.076 \times R_{p t}^{0.67}(\mathrm{~dB} / \mathrm{km})
$$

\subsection{Link Margin Analysis}

For a reliable communication system, one crucial task of a good communication system designer is to carry out link power budget analysis. This analysis simply entails the inclusion of all known powerloss sources into the transmitting power, with the intention of ensuring a certain minimum power reaches the receiver on the other end of the link. In this study, the loss sources considered in the link budgeting were fog- and rain-induced specific attenuations. Link margin is the difference between the receiver's sensitivity (i.e., the received power below which the receiver will stop working) and the expected minimum received power. If the link margin is lower than a minimum value required by a receiver to function properly (receiver sensitivity), the system will be unavailable. The link margin is defined as [10]:

$$
L M(\mathrm{~dB})=P_{t}+\left|S_{r}\right|-A t t_{G e o}-\Sigma A t m_{\text {Losses }}
$$

where $P_{t}$ is the transmitted power in $(\mathrm{dBm}),\left|S_{r}\right|$ is the absolute value of the receiver sensitivity in $(\mathrm{dBm})$, $A t t_{G e o}$ is the geometric loss (in $\mathrm{dB}$ ), and $\Sigma A t m_{\text {Losses }}$ is the summation of the various atmospheric losses in $(\mathrm{dB})$. The geometric loss in decibel is thus given as [1]:

$$
A t t_{G e o}=-20 \log \left[\frac{d_{r}}{\left(d_{t}+\theta_{b} L_{d}\right)}\right]
$$

where $d_{r}$ and $d_{t}$ are the receiver and transmitter aperture diameters respectively (in $\mathrm{cm}$ ), $\theta_{b}$ is the beam divergence angle (in $\mathrm{mrad}$ ), and $L_{d}$ is the FSO link distance (in $\mathrm{km}$ ). To carry out a realistic link power budgeting for this study, the parameters of a commercial optical transceiver (TereScope 5000) presented in

\begin{tabular}{|c|c|c|}
\hline \multicolumn{2}{|r|}{ Device Parameter } & Value \\
\hline & & TS5000/4E1 \\
\hline \multicolumn{2}{|r|}{$\begin{array}{c}\text { Model } \\
\text { Standard P. N. }\end{array}$} & TS5000/4E1/V \\
\hline \multirow{4}{*}{\multicolumn{2}{|c|}{ Typical Application / Data Protocol }} & Ethernet / $(10 \mathrm{Mbps})$ \\
\hline & & Fast Ethernet / $(1-155 \mathrm{Mbps})$ \\
\hline & & Gigabit Ethernet Escon / (622 Mbps) \\
\hline & & Fibre Channel and Others / $(100-1500 \mathrm{Mbps})$ \\
\hline \multirow{5}{*}{ Transmitter } & Light Source & $3 \times$ Lasers \\
\hline & Wavelength & $830-860 \mathrm{~nm}$ \\
\hline & Total Output Power & $85 \mathrm{~mW}$ \\
\hline & Beam Divergence Angle & $2 \mathrm{mrad}$ \\
\hline & Transmit Aperture Diameter & $3 \mathrm{~cm}$ \\
\hline \multirow{4}{*}{ Receiver } & Detector & APD \\
\hline & Field of view & $2 \mathrm{mrad}$ \\
\hline & Sensitivity & $-46 \mathrm{dBm}$ \\
\hline & Receive Aperture Diameter & $10 \mathrm{~cm}$ \\
\hline
\end{tabular}
Table 1 was adopted [11].

Table 1. Terescope ${ }^{\circledR} 5000$ technical specifications

The first scenario considers only geometric loss and fog-induced loss such that the (5) becomes:

$$
L M_{G e o \& F o g}(\mathrm{~dB})=P_{t}+\left|S_{r}\right|-A t t_{G e o}-A t t_{F o g}
$$

where

$$
A t t_{F o g}=10 \log \left(e^{-\beta_{\text {spec }} \times L_{d}}\right)
$$

APTIKOM J. CSIT Vol. 4, No. 3, 2019: 125-134 
By substituting (6) and (8) into (7), it yields:

$$
L M_{\text {Geo\&Fog }}(\mathrm{dB})=P_{t}+\left|S_{r}\right|-20 \log \left[\frac{d_{r}}{\left(d_{t}+\theta_{b} L_{d}\right)}\right]-\left[10 \log \left(e^{-\beta_{\text {spec }} \times L_{d}}\right)\right]
$$

The fog-induced loss was computed at five optical wavelengths of $650,750,850,950$ and 1550 $\mathrm{nm}$, link distances $\left(L_{d}\right)$ of $1,2,3,4,5, \ldots, 10 \mathrm{~km}$ and $2 \%$ transmittance threshold at a visibility value of 5 $\mathrm{km}$. The selected visibility value represents a frequent visibility range for the study location.

The second loss scenario considers only geometric loss and rain-induced loss such that (5) becomes:

$$
L M_{\text {Geo\&Rain }}(\mathrm{dB})=P_{t}+\left|S_{r}\right|-A t t_{\text {Geo }}-A t t_{\text {Rain }}
$$

where

$$
A t t_{\text {Rain }}=\left(1.076 \times R_{p t}^{0.67}\right) \times L_{d}
$$

By substituting (6) and (11) into (10), it yields:

$$
L M_{\text {Geo\&Rain }}(\mathrm{dB})=P_{t}+\left|S_{r}\right|-20 \log \left[\frac{d_{r}}{\left(d_{t}+\theta_{b} L_{d}\right)}\right]-\left[\left(1.076 \times R_{p t}^{0.67}\right) \times L_{d}\right]
$$

where all parameters retain their previous definitions, and $L_{d}$ is the link distance $(\mathrm{km})$. The raininduced loss was computed at rain rates of 20,40,80, 120 and $200 \mathrm{~mm} / \mathrm{hr}$. These values were picked to cover both convective and stratiform rainfall observed in the study area. The computations were carried out at the same set of link distances.

\section{Results and Discussion}

Figure 1 shows the estimated specific attenuation at 650, 850 and $1550 \mathrm{~nm}$ wavelengths based on $2 \%$ transmittance threshold against daily visibility over a year using Kruse model. Three peak values were observed on three foggy atmospheric conditions. These could be seen at the 35th, 269th and 317th days of the year with visibility value as low as $0.3 \mathrm{~km}$ with maximum specific attenuation values $(\mathrm{dB} / \mathrm{km})$ of 122.14 , 109.96 and 86.91 at 650,850 and $1550 \mathrm{~nm}$ wavelengths respectively. The estimated attenuation decreases by $9.97 \%$ from the value at $650 \mathrm{~nm}$ to that at $850 \mathrm{~nm}$. However, from $650 \mathrm{~nm}$ to $1550 \mathrm{~nm}$, attenuation values decrease by about $28.84 \%$. Another foggy event of lower intensity was observed on the 351 st day of the year with a visibility value 3 of $0.5 \mathrm{~km}$.

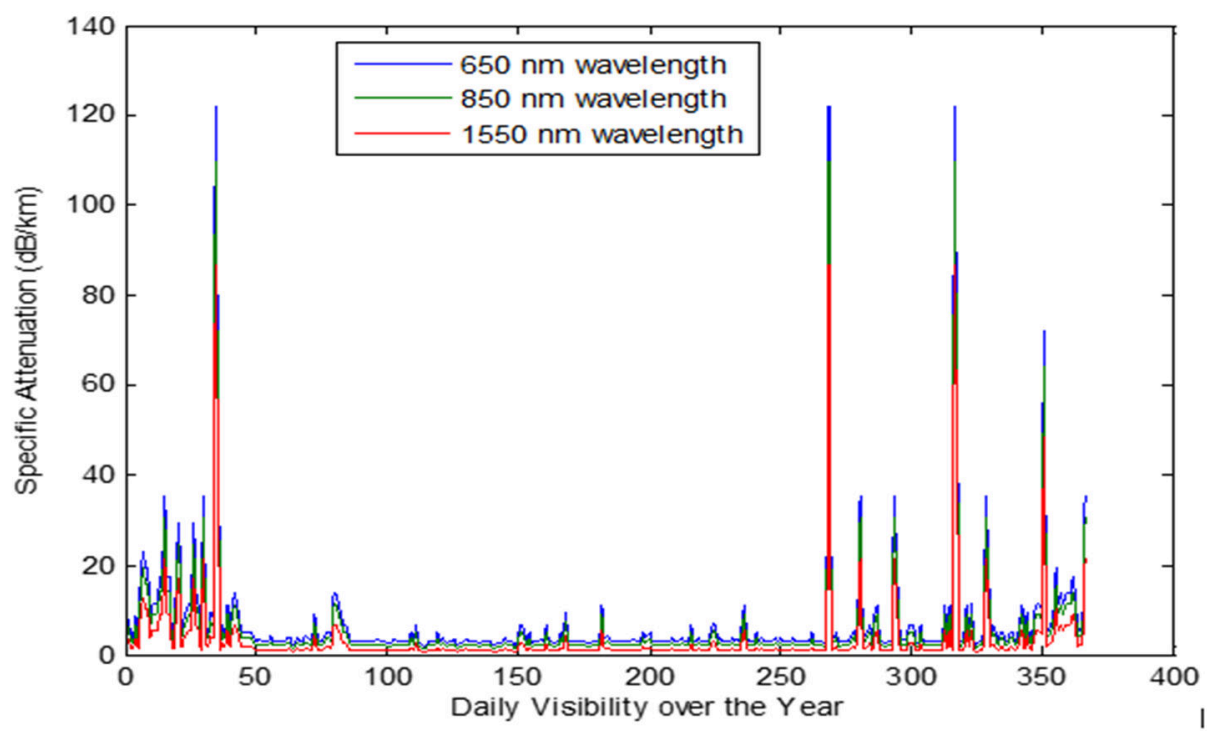

Figure 1. Estimated specific attenuation for different wavelengths using Kruse model at 2\% transmittance threshold 
Another analysis carried out in this study was the probability distribution of grouped specific attenuation occurrence at the study area. The result on estimated specific attenuation was used to compute the percentage probability of occurrence of grouped specific attenuation values (with a class width of 5) at five optical wavelengths of $650,750,850,950$ and $1550 \mathrm{~nm}$, and $2 \%$ transmittance thresholds. Figure 2 presents the probability distribution of specific attenuation occurrence against the upper boundaries of grouped specific attenuation. It was observed that the most probable estimated specific attenuation at 650 $\mathrm{nm}$ ranges from $0.00-5.00 \mathrm{~dB} / \mathrm{km}$ with a percentage probability value of about $67.38 \%$. For the $850 \mathrm{~nm}$ wavelength, the same attenuation range is the most probable with a percentage probability of about $75.95 \%$. At the same optical wavelength of $650 \mathrm{~nm}$, the second most probable specific attenuation range from 5.01$10.00 \mathrm{~dB} / \mathrm{km}$, with a percentage probability of about $18.54 \%$. At $1550 \mathrm{~nm}$ wavelength, a similar trend was observed with a percentage probability of about $1.52 \%$ for specific attenuation range from 10.01-15.00 $\mathrm{dB} / \mathrm{km}$. This implies that Akure can be characterized as a low fog-induced specific attenuation location. The summary of the percentage probability of fog-induced specific attenuation is as presented in Table 2 .

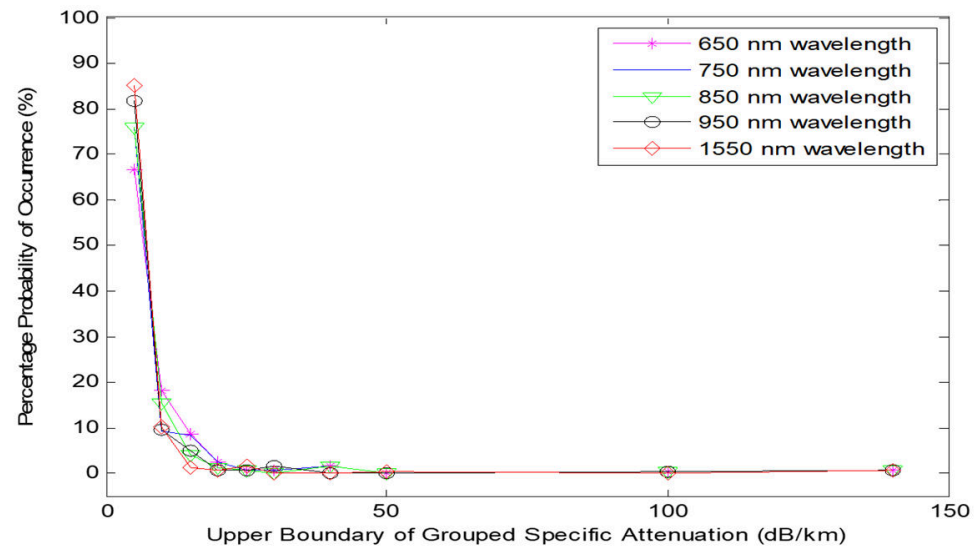

Figure 2. Probability of specific attenuation at different wavelengths and $2 \%$ transmittance thresholds

Table 2. Summary of percentage probability of fog-induced specific attenuation at akure

\begin{tabular}{cccccc}
\hline $\begin{array}{c}\text { Specific Attenuation } \\
\text { Range }(\mathrm{dB} / \mathrm{km})\end{array}$ & \multicolumn{5}{c}{$\begin{array}{c}\text { Percentage Probability of Encountering Attenuations at Different Wavelengths (nm) } \\
\text { and } \% \text { Transmittance Threshold }\end{array}$} \\
\hline $0 \leq \beta \leq 5$ & 650 & 750 & 850 & 950 & 1550 \\
$5<\beta \leq 10$ & 67.38 & 76.20 & 75.95 & 82.44 & 86.00 \\
$10<\beta \leq 15$ & 18.54 & 9.68 & 16.14 & 10.10 & 10.50 \\
$15<\beta \leq 20$ & 8.75 & 9.02 & 4.30 & 4.68 & 1.52 \\
$20<\beta \leq 25$ & 2.50 & 2.50 & 1.68 & 0.80 & 0.50 \\
$25<\beta \leq 30$ & 0.80 & 0.80 & 0.50 & 0.50 & 0.80 \\
$30<\leq 35$ & 0.50 & 0.30 & 0.00 & 0.80 & 0.00 \\
$35<\leq 40$ & 0.00 & 0.80 & 0.80 & 0.00 & 0.00 \\
$\beta>40$ & 0.80 & 0.00 & 0.00 & 0.00 & 0.30 \\
\hline
\end{tabular}

Figure 3 presents the estimated rain-induced specific attenuation against rain rates in November and March, which marked the beginning and end of the dry season months respectively. It was observed that the maximum specific attenuation in November is about $18.82 \mathrm{~dB} / \mathrm{km}$ while that of March is about $21.38 \mathrm{~dB} / \mathrm{km}$. Other months in the dry season show similar trend with the highest specific attenuation observed in February, 2014. The maximum estimated specific attenuation for the month is about 27.57 $\mathrm{dB} / \mathrm{km}$. Figure 4 also presents the estimated rain-induced specific attenuation against rain rates in April and October, which marked the beginning and end of the raining season months respectively. The maximum estimated specific attenuation in April is about $28.87 \mathrm{~dB} / \mathrm{km}$. For the month of October, the maximum specific attenuation is about $27.98 \mathrm{~dB} / \mathrm{km}$. In terms of peak estimated specific attenuation, the worst month whereby the greatest impairment along the FSO link is May with peak attenuation value of about 34.90 $\mathrm{dB} / \mathrm{km}$. Generally speaking, there are few cases of estimated specific attenuation in order of 20 and 30 $\mathrm{dB} / \mathrm{km}$, yet the overall effect of rain on the proposed link is low due to the low average values in each month of the study. The summary of the rain-induced specific attenuation is as presented in Table 3 .

APTIKOM J. CSIT Vol. 4, No. 3, 2019: 125 - 134 


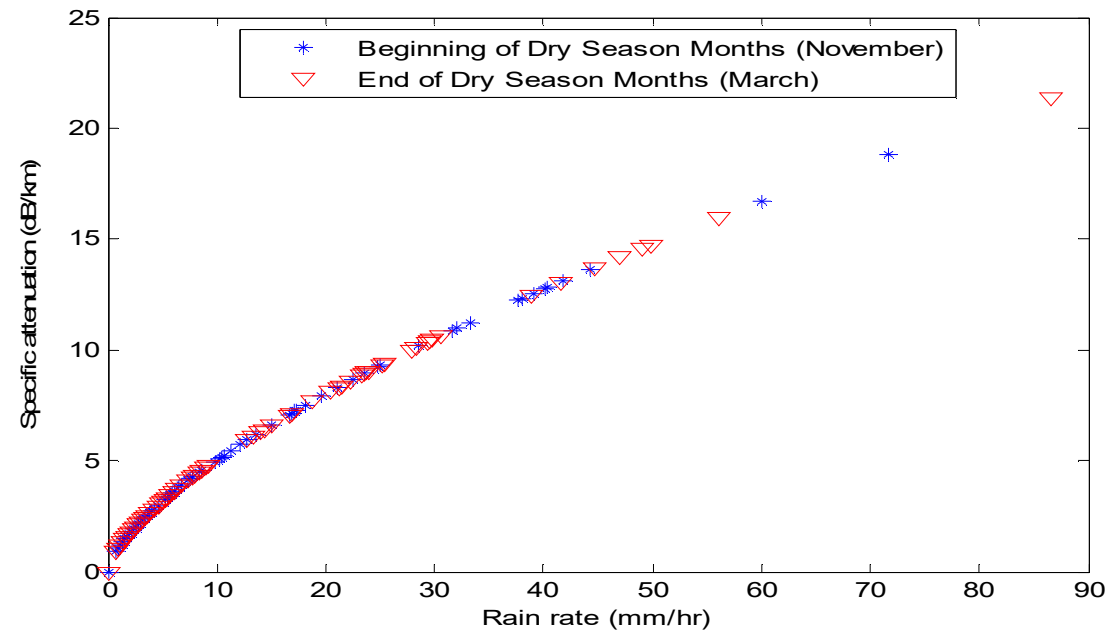

Figure 3. Estimated rain-induced specific attenuation at the beginning and end of dry season months

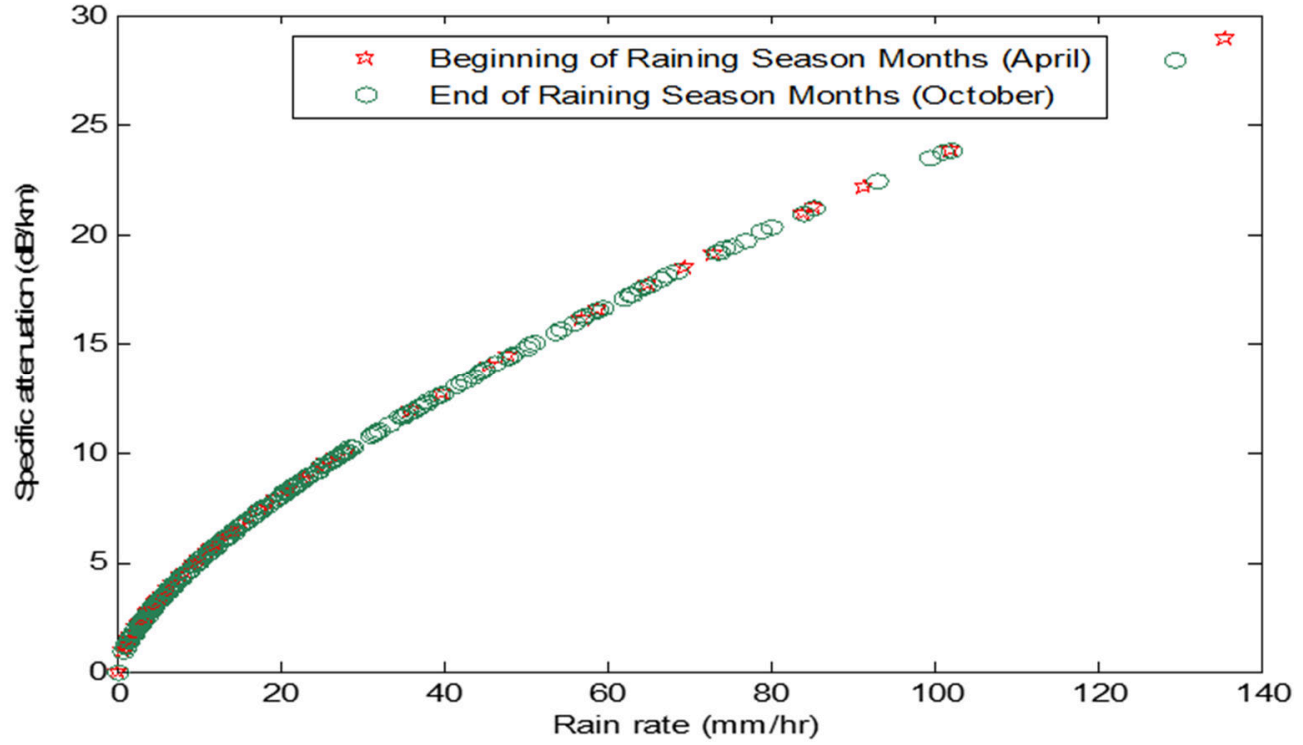

Figure 4. Estimated rain-induced specific attenuation at the beginning and end of raining season months

Table 3. Summary of estimated rain-induced specific attenuation at Akure from November, 2013 to

\begin{tabular}{|c|c|c|c|}
\hline \multirow{3}{*}{ MONTH } & \multicolumn{2}{|c|}{ October, 2014} & \\
\hline & \multicolumn{3}{|c|}{ Estimated Rain-induced Specific Attenuation $(\mathrm{dB} / \mathrm{km})$} \\
\hline & Min. Value & Max. Value & Average Value \\
\hline November & 0.00 & 18.82 & 5.99 \\
\hline December & 0.00 & 26.42 & 10.60 \\
\hline January & 0.00 & 26.06 & 8.78 \\
\hline February & 0.00 & 27.57 & 8.94 \\
\hline March & 0.00 & 21.38 & 6.33 \\
\hline April & 0.00 & 28.87 & 7.15 \\
\hline May & 0.00 & 34.90 & 10.93 \\
\hline June & 0.00 & 29.10 & 10.81 \\
\hline July & 0.00 & 16.15 & 5.46 \\
\hline August & 0.00 & 29.10 & 8.62 \\
\hline September & 0.00 & 30.83 & 10.79 \\
\hline October & 0.00 & 27.98 & 9.54 \\
\hline
\end{tabular}

The expected performance of an FSO system in the study area is evaluated by link margin analysis based on the parameters of Terescope 5000. The first scenario considered in the link margin analysis is the 
combined effects of geometric loss and atmospheric loss due to reduced visibility. The results are presented in Figure 5. At $2 \mathrm{~km}$ distance for example, the link margins are 4.69, 12.36, 18.23, 22.85 and $38.09 \mathrm{~dB}$ at $650,750,850,950$ and $1550 \mathrm{~nm}$ wavelengths respectively. With the sensitivity of Terescope 5000 being $46 \mathrm{dBm}$, the FSO link will be available at all five wavelengths at the $2 \mathrm{~km}$ link distance. At $5 \mathrm{~km}$, the values are $-76.18,-57.01,-42.35,-30.77$ and 7.30 at $650,750,850,950$ and $1550 \mathrm{~nm}$ wavelengths respectively. At an increased link distance of $5 \mathrm{~km}$, the system will only be available at higher wavelengths of 850,950 and $1550 \mathrm{~nm}$. The system gets worse at a link range of $10 \mathrm{~km}$ where the link margins are as low as -214.98 $\mathrm{dB}$ at $650 \mathrm{~nm},-176.63 \mathrm{~dB}$ at $750 \mathrm{~nm},-147.31 \mathrm{~dB}$ at $850 \mathrm{~nm},-124.16 \mathrm{~dB}$ at $950 \mathrm{~nm}$, and $-48.01 \mathrm{~dB}$ at 1550 $\mathrm{nm}$ wavelength. At $2 \mathrm{~km}$ link range, the link margin increased by $711.79 \%$ from $650 \mathrm{~nm}$ to $1550 \mathrm{~nm}$ wavelength while at $5 \mathrm{~km}$ distance, the increase in link margin between the same set of wavelengths is $109.59 \%$. Although transmission at higher optical wavelengths reduce attenuation on an FSO link, however these results revealed that the adoption of a higher operating wavelength becomes less important as the link range increases. The summary of the link margin is as presented in Table 4.

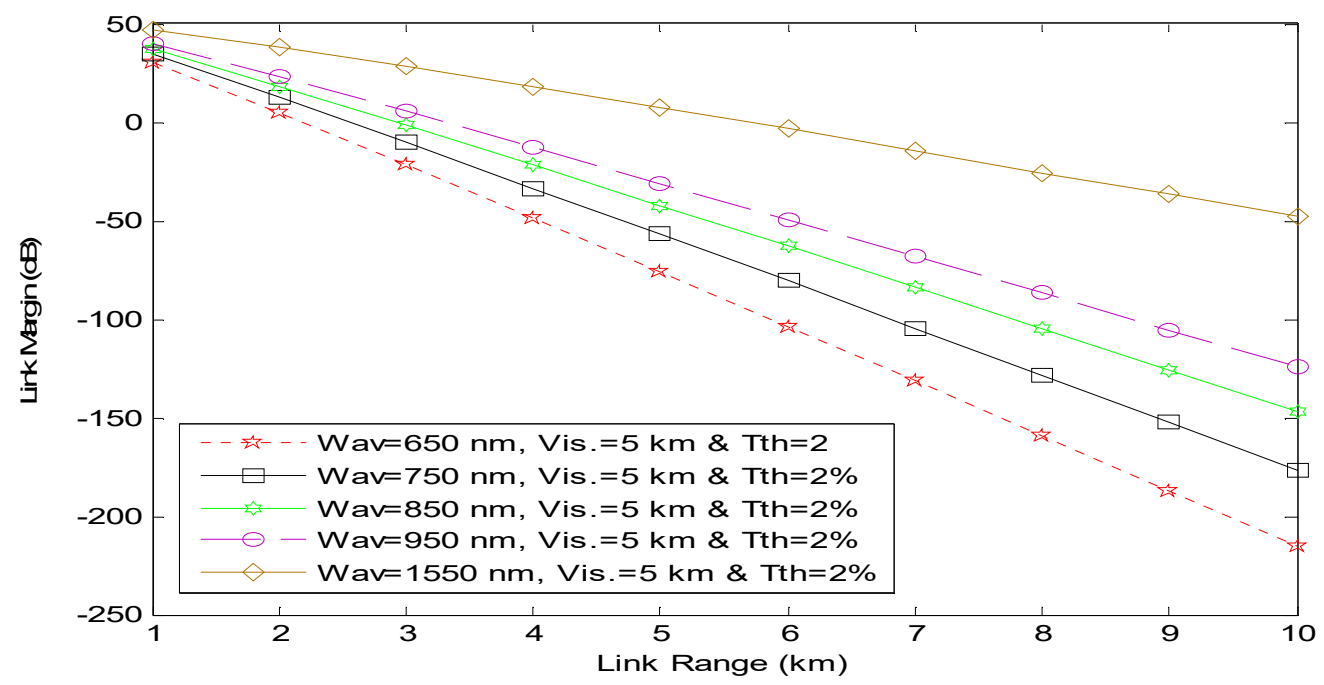

Figure 5. Link margin with geometric and atmospheric losses at $5 \mathrm{~km}$ visibility, $2 \%$ transmittance threshold and different wavelengths and link ranges

Table 4. Summary of link margin for combined effect of geometric and fog-induced losses

\begin{tabular}{cccccc}
\hline $\begin{array}{c}\text { Link Range } \\
(\mathrm{km})\end{array}$ & \multicolumn{4}{c}{ Link Margin (Geometric \& Fog) for 5 km Visibility and 2\% Transmittance threshold } \\
\hline 1 & $650 \mathrm{~nm}$ & $750 \mathrm{~nm}$ & $850 \mathrm{~nm}$ & $950 \mathrm{~nm}$ & $1550 \mathrm{~nm}$ \\
\hline 2 & 30.52 & 34.36 & 37.29 & 39.60 & 47.22 \\
3 & 4.69 & 12.36 & 18.23 & 22.85 & 38.09 \\
4 & -21.88 & -10.37 & -1.58 & 5.37 & 28.23 \\
5 & -48.88 & -33.54 & -21.82 & -12.56 & 17.91 \\
6 & -76.18 & -57.01 & -42.35 & -30.77 & 7.30 \\
7 & -103.69 & -80.68 & -63.09 & -49.20 & -3.51 \\
8 & -131.35 & -104.51 & -83.99 & -67.78 & -14.47 \\
9 & -159.14 & -128.46 & -105.00 & -86.48 & -25.56 \\
10 & -187.02 & -152.51 & -126.12 & -105.28 & -36.74 \\
\hline
\end{tabular}

Figure 6 shows the plots of the link margins due to the combined effects of geometric loss and atmospheric loss due to rain. At $2 \mathrm{~km}$, the link margins are 46.18, 36.71, 21.65, 8.99 and $-12.72 \mathrm{~dB}$ at 20, $40,80,120$ and $200 \mathrm{~mm} / \mathrm{hr}$ rain rates respectively. The link remains available even at a rain rate of 200 $\mathrm{mm} / \mathrm{hr}$. At $5 \mathrm{~km}$ link range, the link margins are $27.53,3.87,-33.79,-65.43$ and $-119.70 \mathrm{~dB}$ at the stated rain rates respectively. The link becomes unavailable at higher rain rates of 120 and $200 \mathrm{~mm} / \mathrm{hr}$. The results at the link range of $10 \mathrm{~km}$ show the least link margins of $-7.55 \mathrm{~dB}$ at $20 \mathrm{~mm} / \mathrm{hr},-54.88 \mathrm{~dB}$ at $40 \mathrm{~mm} / \mathrm{hr}$, $130.19 \mathrm{~dB}$ at $80 \mathrm{~mm} / \mathrm{hr},-193.46 \mathrm{~dB}$ at $120 \mathrm{~mm} / \mathrm{hr}$ and $-302.02 \mathrm{~dB}$ at $200 \mathrm{~mm} / \mathrm{hr}$, being available only at $20 \mathrm{~mm} / \mathrm{hr}$. At $20 \mathrm{~mm} / \mathrm{hr}$ rain rate, the link margin is reduced by $40.38 \%$ from the $2 \mathrm{~km}$ range to the $5 \mathrm{~km}$ range. From the $5 \mathrm{~km}$ range to the $10 \mathrm{~km}$ range, the link margin further decreases by $127.43 \%$. At 200

APTIKOM J. CSIT Vol. 4, No. 3, 2019 : 125 - 134 
$\mathrm{mm} / \mathrm{hr}$ rain rate, the link margin is reduced by $841.30 \%$ from the $2 \mathrm{~km}$ range to the $5 \mathrm{~km}$ range, and $152.31 \%$ from the $5 \mathrm{~km}$ range to the $10 \mathrm{~km}$ range. These results show that the percentage decrease in link margin is much higher at higher rain rates and with shorter link ranges. The summary of the link margins due to the combined effects of geometric and rain-induced losses are presented in Table 5.

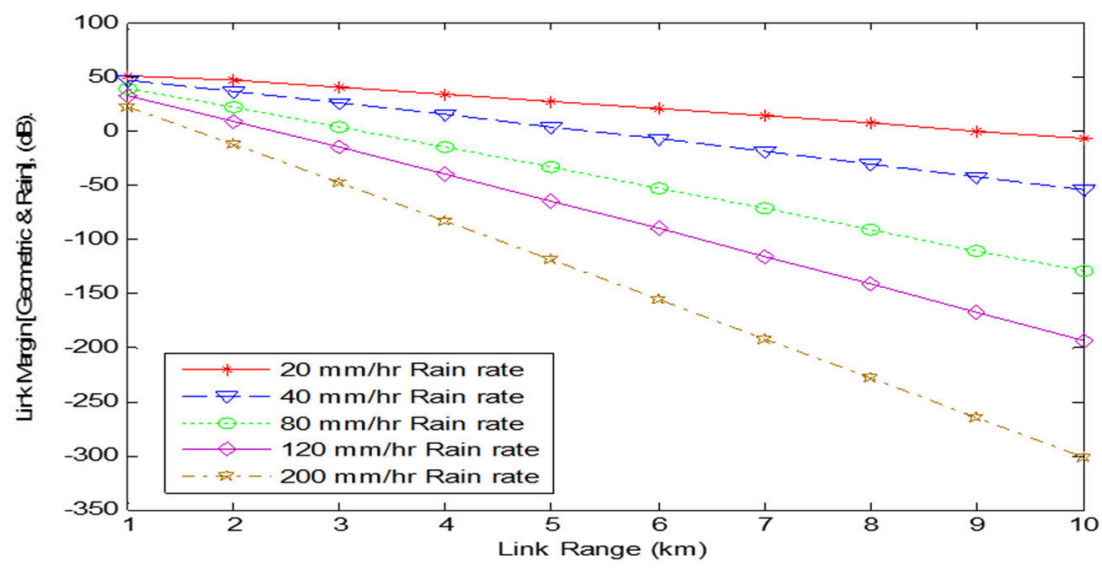

Figure 6: Link margin with geometric and rain losses at different rain rates and link ranges

Table 5. Summary of link margin for combined effect of geometric and rain-induced losses

\begin{tabular}{cccccc}
\hline \multirow{2}{*}{ Link Range $(\mathrm{km})$} & \multicolumn{5}{c}{ Link Margin $($ Geometric \& Rain), Db } \\
& $20 \mathrm{~mm} / \mathrm{hr}$ & $40 \mathrm{~mm} / \mathrm{hr}$ & $80 \mathrm{~mm} / \mathrm{hr}$ & $120 \mathrm{~mm} / \mathrm{hr}$ & $200 \mathrm{~mm} / \mathrm{hr}$ \\
\hline 1 & 51.26 & 46.53 & 39.00 & 32.67 & 21.82 \\
2 & 46.18 & 36.71 & 21.65 & 8.99 & -12.72 \\
3 & 40.35 & 26.15 & 3.56 & -15.42 & -47.99 \\
4 & 34.09 & 15.16 & -14.97 & -40.28 & -83.70 \\
5 & 27.53 & 3.87 & -33.79 & -65.43 & -119.70 \\
6 & 20.77 & -7.63 & -52.82 & -90.78 & -155.91 \\
7 & 13.85 & -19.29 & -72.00 & -116.29 & -192.28 \\
8 & 6.80 & -31.06 & -91.31 & -141.93 & -228.77 \\
9 & -0.33 & -42.93 & -110.71 & -167.66 & -265.35 \\
10 & -7.55 & -54.88 & -130.19 & -193.46 & -302.02 \\
\hline
\end{tabular}

\section{Conclusion}

In this study, fog- and rain-induced specific attenuations have been investigated for terrestrial FSO communication in Akure, Ondo State, Nigeria. Retrieved one-year archived visibility and rain data have been used to compute both fog- and rain-induced losses at five optical wavelengths of 650, 750, 850, 950 and $1550 \mathrm{~nm}$, at $2 \%$ transmittance thresholds. Results on the fog-induced specific attenuation shows peak values of about $122.14,109.96$ and $86.91 \mathrm{~dB} / \mathrm{km}$ at 650,850 and $1550 \mathrm{~nm}$ wavelengths respectively. The result shows that fog-induced specific attenuation generally decreases with increasing optical wavelength. These maximum values occur thrice throughout the year of study. Although these high values potent danger for an FSO link, however results from the percentage probability of fog-induced specific attenuation occurrence have shown that the most probable specific attenuation ranges from $0.00-5.00 \mathrm{~dB} / \mathrm{km}$ for all the wavelengths considered. This implies that the study location can be characterized as a low attenuation region, thus very suitable for FSO communication system implementation.

The peak value of rain-induced specific attenuation was observed to be about $34.90 \mathrm{~dB} / \mathrm{km}$ in May, 2014 , with a maximum average value of about $10.93 \mathrm{~dB} / \mathrm{km}$ for the period of study. These values are much lower than the peak value of about $122.14 \mathrm{~dB} / \mathrm{km}$ in the foggy atmosphere with a visibility of $0.3 \mathrm{~km}$. The implication is that rain-induced attenuation is much lower than fog-induced attenuation at the study area. This again reaffirms the characterization of the study area as low attenuation region, thus implying that FSO communication system can be suitably implemented at the study area since it is majorly characterized by rainfall.

Results on the link margin analysis considering geometric and fog-induced losses show that the proposed FSO system with a commercial optical transceiver, Terescope 5000 gives acceptable performance at $2 \mathrm{~km}$ link distance at all the wavelengths considered. At a farther link distance of $5 \mathrm{~km}$, the link will only 
perform suitably at higher wavelengths of 950 and $1550 \mathrm{~nm}$. At $10 \mathrm{~km}$ link distance, the system fails at all wavelengths except at $1550 \mathrm{~nm}$. Although transmission at higher optical wavelengths reduce attenuation on an FSO link, however results have revealed that the adoption of a higher operating wavelength for attenuation reduction becomes less effective as the link range increases.

From the results on the link margin analysis considering geometric and rain-induced losses for the same FSO system, a similar trend was observed as the system performs well at $2 \mathrm{~km}$ link distance at the five considered rain rates. At $5 \mathrm{~km}$ link distance however, the system is unavailable at higher rain rates of 120 and $200 \mathrm{~mm} / \mathrm{hr}$. At a further link distance of $10 \mathrm{~km}$, the link is only available at a rain rate of $20 \mathrm{~mm} / \mathrm{hr}$. Results have shown that percentage decrease in link margin is much higher during shower and thunderstorm (with associated high rain rates). This implies that an FSO system is more prone to link outage at higher rain rate and longer link ranges.

\section{Recommendations}

Based on the findings from this study, the following recommendations are proposed:

- with the low average estimated rain-induced specific attenuation and acceptable link margins at low rain rates, the adoption and installation of short link (few kilometers) FSO communication systems in Akure is strongly recommended; and

- in furtherance of the scope of the current study, longer period (few years) visibility and rain rate data should be used to study the seasonal variability of both fog- and rain-induced attenuations for better system design and implementation at the study location.

\section{References}

[1] Ghassemlooy, Z., Popoola, W., and Rajbhandari, S. Optical Wireless Communications-System and Channel Modelling with MATLAB. CRC Press, Taylor \& Francis Group. 6000 Broken Sound Parkway NW. Suite 300 Boca Raton. 2013: 33487-2742.

[2] Willebrand H. and Ghuman B. S. Free Space Optics-Enabling Optical Connectivity in Today's Networks. Indianapolis. in: Sams Publishing. 2002.

[3] Andrews L. C., Phillips R. L., and Hopen C. Y. Laser Beam Scintillation with Applications. Bellingham. WA: SPIE Press. 2001.

[4] Awan, M. S., Leitgeb, E., Capsoni, C., Nebuloni, R., Marzuki, Nadeem, F. and Khan, M. S. Attenuation Analysis for Optical Wireless Link Measurements under Moderate Continental Fog Conditions at Milan and Graz. IEEE. 2008. 1-4244-1722-3.

[5] Flecker, B., Gebhart, M., Leitgeb, E., Sheikh, M, and Chlestil, C. Results of attenuation measurements for optical wireless channel under dense fog conditions regarding different wavelengths. In Proc. SPIE. 2006. Vol.6303.

[6] Awan, M. S., Leitgeb, E., Horwath, L. C., Muhammad, S. S., Nadeem, F., and Khan, M. S. Characterization of Fog and Snow Attenuations for Free-Space Optical Propagation. Journal of Communications. 2009. Vol.4(8): 533-545.

[7] Adimula, I. A. Characteristics of Rain Induced Attenuation and Phase shift in Ilorin. Nigeria. Zuma Journal of Pure and Applied Science. 2003. Vol.5(2): 193-196.

[8] Hall, P. M., Braclay, L.W., and Hewitt, M. T. Propagation of Radiowaves. IEE Press. London. 1996.

[9] Mohamed, O. T., Mahmud, M. B., and Adam, F. A. Analysis of Rain Effects on Free Space Optics Based on Data Measured in the Lybyan Climate. International Journal of Information and Electronics Engineering. 2014. vol.4(6): 469-472.

[10] Rouissat, M., Borsali, A. R. and Chikh-bled, M. E. Free Space Optical Channel Characterization and Modelling with Focus on Algeria Weather Conditions. I. J. Computer Natwork and Information Security. 2012. Vol.3: 1723.

[11] MRV Communications, Terescope 5000 Datasheet. http://www.mrvfso.com/mrvsupport. 2002. 